Teosofia: Indonesian Journal of Islamic Mysticism, Volume 5, Number 2, 2016

DOI: http://dx.doi.org/10.21580/tos.v5i2.1726

\title{
رعاية البيئة في التصوف الإسلامي
}

\author{
Ahmad Munji \\ Marmara University, Turki \\ amunji@gmail.com
}

\begin{abstract}
As a universal religion, Islam regulates all aspects of life. As one of aspects in Islam, tasawwuf/Sufism invites people to be guardians for environmental preservation since nature is part of God's creatures. To some extent, the teachings of Sufism are mainly about ethic (adab). This ethic can be either vertical to God or horizontal to all God's creatures including nature and environment. Ibn Arabi in this regard is an influential character in Sufism which his thoughts gave a lot of influence on the development of the world of Sufism in General. Among his thoughts is about the unity of God with the universe. The question is, how Ibn Arabi's thought could give an impact in the context of the preservation of the environment. This research finds amd formulates some aspect of Sufism that can contribute to encourage people in dealing with environmental preservation. It is based on attitude or akhlak theologically.
\end{abstract}

Keyword: Sufism, nature, environment, preservation.

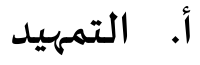

العالم لله مكانة عالية لأناه سبيل لمعرفة الخالق. العالم يدل على وجودالله تعالى. كل يسبح

بحمده.' و الإسلام يرى أن كل مخلوق خلقه الله له دور مهم لاستمرار حياة مخلوقات أخرى. 'أوضح هذه

النظرية بأن كل مخلوق-حتى أصغر مخلوق لله يكون دليلا على وجود الله. و أشد من ذلك, نظر سيد

حسين نصر(ع999) بأن العالم وما فياه من الحيوانات, و النباتات, و الشمس, و القمر, و الأرض برها

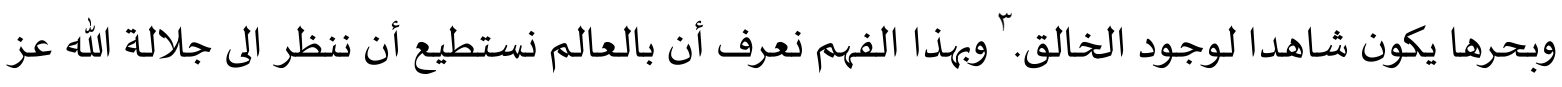

$$
\begin{aligned}
& \text { 'الأنبياء: بr, الكهف: عـ. }
\end{aligned}
$$

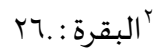

${ }^{3}$ Sayyed Hossein Nasr, “Islam dan Krisis Lingkungan” dalam "Islamika” (Jakarta: Mizan dan Missi, 1994), 5. 
الكون أو الطبيعة تعكس وجود الله خالق كل شي بقصد معين يختلف باختلاف انوع خلقاء. رأى محمد عبده(ت.0 . 19 م) أن المخلوقات كلها أيات لله تعالى, وحركتها دليل على كمال نظاهها التابع لكمال خلقها. و هذا يعني أن بين العالم و الخالق صهلة وثيقة لا يمكن لإنسان أن يطيع الله تعالى ويفهم حقيقة وجوده الا من خلال فهم هذه الصلة. العلم بالعالم في الإسلآم ليس بمجرد علم البيئة, لأن به يمكن الوصهول الى معرفة الله و محبته. قال ابن عطاء الله السكندري(ت.9 . . ) في حكماه: الكون كله ظلمة وإنما إنارته إظهار الحق فياء, فمن رأى الكون ولم يشهده فياه أو عنده أو قبله أو بعده فقد أعوزه وجود الأنوار وحجبت عنه شمس المعارف بسحب الأثار. و إذا أوجب الله تعالى الإنسان فهم الموجد فوجب على على الإنسان فهم وجود العالم. لأن وجود الله في الدنيا هو العالم وما فياه. فمن يرغبأن يرى ربه قبل الموت فعلياء نظر العالم وما حوله.

ويتركز الباحث في الكشف عن هذا الحل حول علم التصوف باعتباره لب الدين الإسلامى. و بالخصوص آراء الشيخ الأكبر ابن عربي الصوفي. ذلك لأننا عند الحديث عن موضع ما نحتاج الى شخصية له باع طويل حول الموضع. فالشيخ ابن عربي(ت. .ع أم) لله اثار عميقة في العالم الإسلامي بحيث لايمكن فهم تاريح الإسلام بعد عصره إلا بفهم أفكاره. إلا أننا في صعيد الواقع قلة اهتمام المسلمين خاصية أهل السنة و الجماعة بدراسة أفكارهذا الرجل. مع أن الرجل لله إهتمام كبير بالعالم. وهذا ناشيء من النزعة

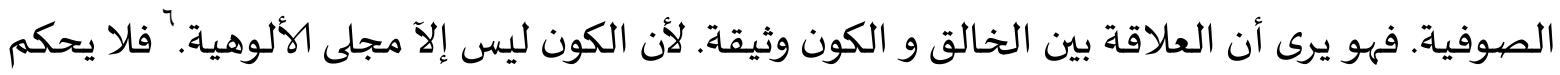

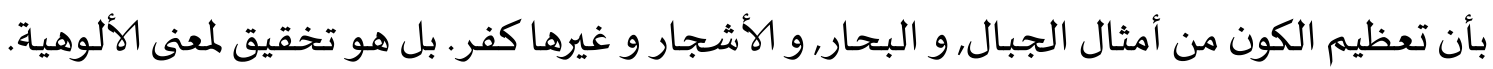

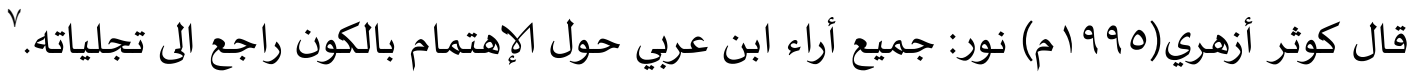

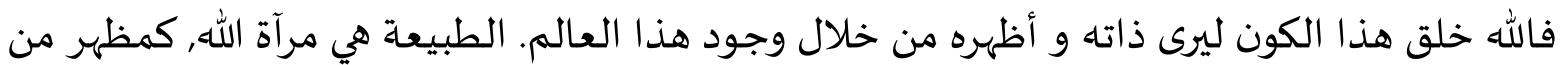

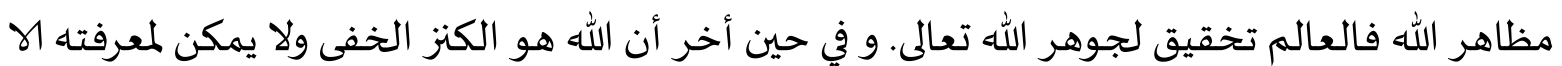

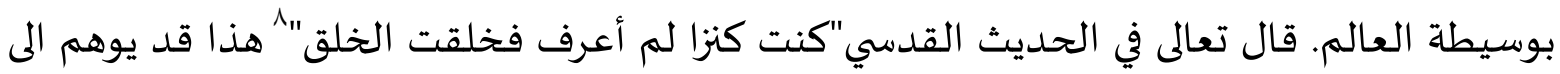

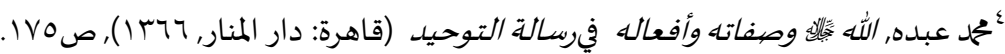

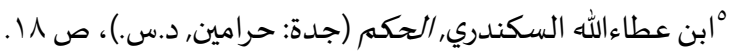

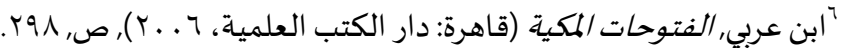

${ }^{7}$ KautsarAshariNoer, IbnArabi: WahdatulWujuddanPerdebatan (Jakarta: Paramadina, 1995),58.

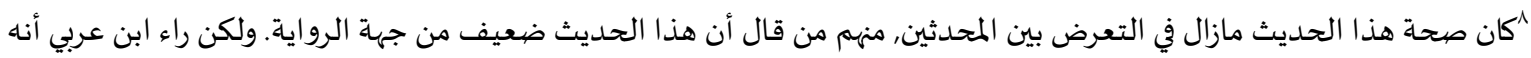

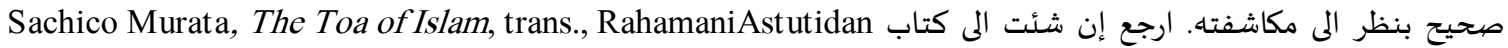


Ri'āyah al-Bī'ah...

(pantheisme) الألوهية.

و لابن عربي(ت. .ع ا م) نظرية أخرى. و هي نظرية الإنسان الكامل. و هذا الإسم أظهره في

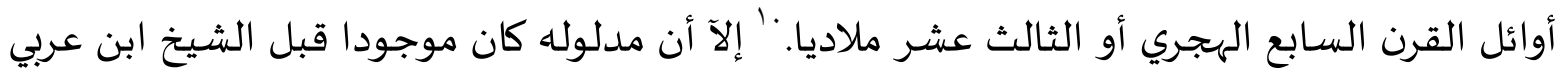

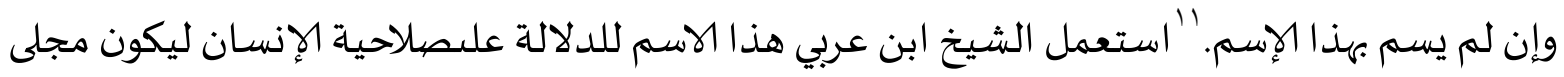
الأ لوهية. فهل كل أحد يمكن أن يسمى الإنسان الكامل؟ جزم الشيخ بعدم إمكاناه وان كان لكل أحد

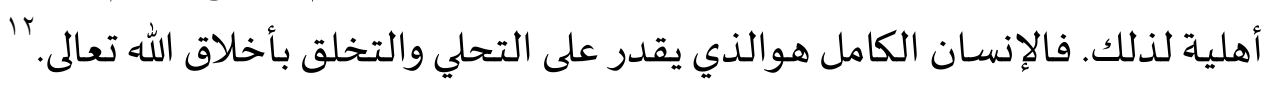
البحث فيما يتعلق بالأخلاق والحفاظ على البيئة، فقد عرض ابن طفيل في قصتئه المشهورة (حي بن يقظان) رؤية فلسفية أخلاقية حول علاقة الإنسان ببيئتها وأهمية الحفاظ على الحئل الحياة البرياة، فيرى أن الأخلاق الحميدة هي التي لا تعترض الطبيعة في سيرها والتي تحول دون تحقيق الغاية الخاصة بالموجودات، فالفاكهة مثلا تخرج من زهرتها ثم تنمو وتنضج ثم تسقط نواها على الأرض ليخرج من كل

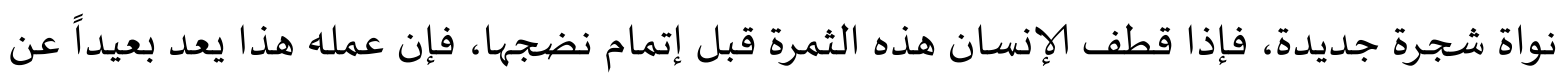
الأخلاق، لأناء يمنع النواة التي لم يتم نموها ونضجهها، قبل أن تحقق غايتها في هذا الوجود وذلك بإخراج

شجرة من نسلها.

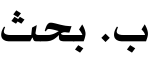

الأخلاق البيئية

قبل الحديث عن مذاهب الناس في الأخلاق البيئية لابد من معرفة معنى الأخلاق البيئية

أولا. هناك كثير من المعاني لهذا الاصطلاح, ولكن اكتفى الباحث بذكر ثلاثة من تلك المعاني وهي كما يلي:

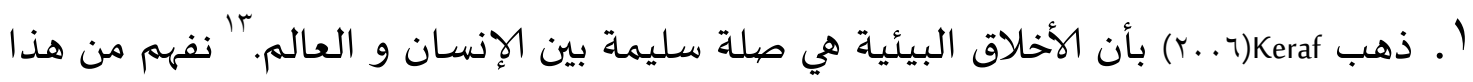

التعريف واجب الإنسان نحو العالم. عليه أن يعيش مع العالم عيشة سليمة.

MS. Nasrullah, Bandung: Mizan, 1996, 39

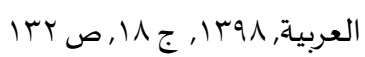
" مفهوم "pantheisme" راء أن وجود الله يمكن أن يورى بواسطة العالم. و هذا المبا المفهوم يمكن أن يكون نقطة الإنطلاق للإهتمام بالبيئة.

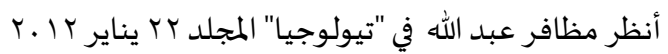

${ }^{10}$ Y unasril Ali, Manusia Citra Ilahi (Jakarta: Paramadina, 1997), 6.

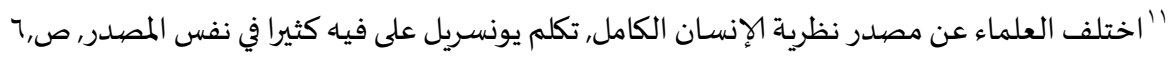

${ }^{12}$ A.Eafifi, Filsafat Mistis Ibn 'Arabi, trans. Sjahrir Mawi (Jakarta: Gaya Media, 1989), 117.

${ }^{13}$ SonyKeraf, EtikaLingkungan (Jakarta: Kompas, 2006), 2.

Teosofia: Indonesian Journal of Islamic Mysticism, Volume 5, Number 2, 2016 


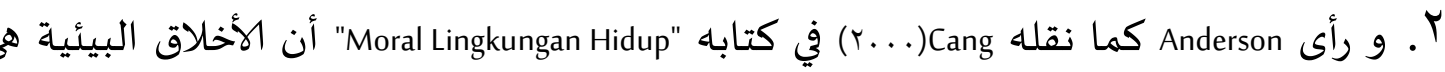

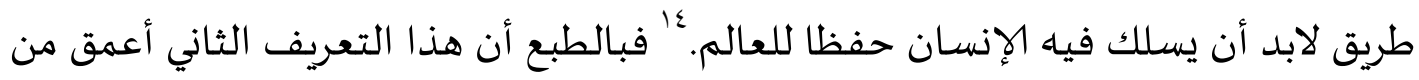

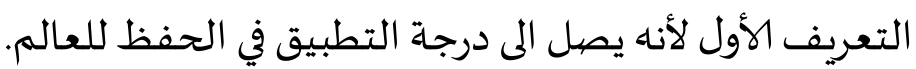

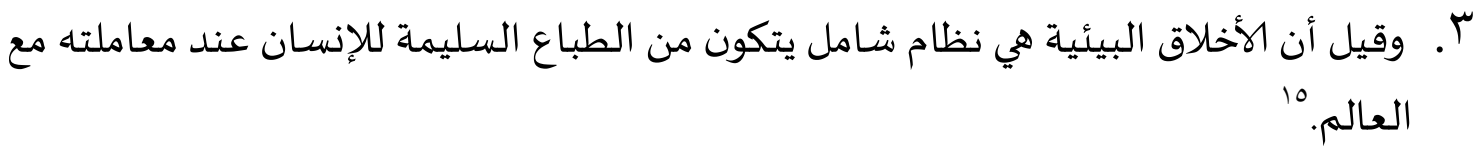

من خلال هذه التعريفات المذكورة يمكن لنا أن نلخص أن الأخلاق البيئية هي العلاقة

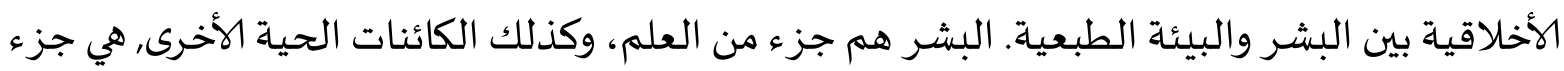
لا يتجزأ من البيئة ويكون بالتالي لحق في أن يعتبر جزءا من حياة الإنسان. و الأخلاق البيئية كآداب

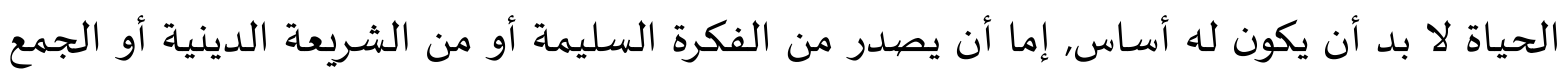
بينهما.

بدأ الحوار عن الأخلاق البيئية بين علماء هذا الفن حول أواخر القرن العشرين ميلاديا. 17 وذلك عند ظهور أول مذهب في هذا الفن يقال له "المركزية البشرية Anthropocentrism". هذا المذهب يرى أن الإنسان يكون مركزا لنظام الكون. معنى هذا أن الإنسان وحوائجه يعتبر من أهم الأمور لاستمرار

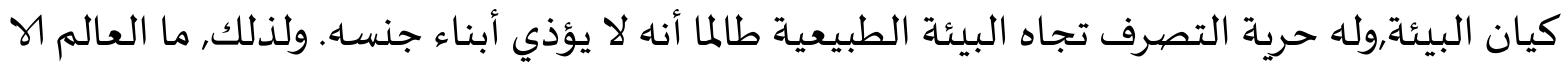
هدفا و وسيلة لإملاء حوائج الناس, و ليس للعالم قيم و نتائج عند هذاالمذهب."أمكن علماء هذا

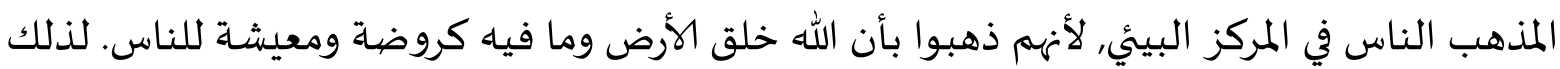
تُعتبَر الأفعال والسياسات "صحيحة" إذا نفعت أفراد البشر ومجتمعاتهم. و خلاصية القول أن البيئة تخلق من أجل إملاء حوائج الناس, و أسـاس رعاية البيئة عند "المركزية البشرية Anthropocentrism" مبني على معرفة أهمية البيئة كوسيلة لإملاء حوائج الناس.

\footnotetext{
${ }^{14}$ William Cang, Moral Lingkungan Hidup (Yogjakarta: Kaniius, 2000), 34.

${ }^{15}$ Abdul Qudus dalam Swito. NS, Eko-Sufisme: Konsep, Strategi dan Dampak (Yogyakarta: ST AIN Press, 2011), 28. 77'البيئة في اللغة تعني الإقامة أو المنزل, يقال تبوء فلان منزلا, أي اتخذ منزلا, و الإسم البيئة و المبائة. أما في المصطلاح العالمى

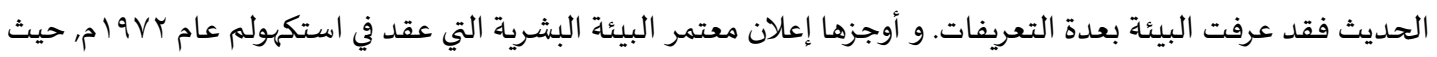

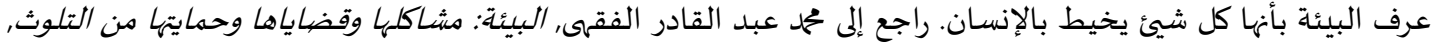

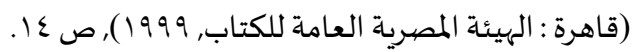

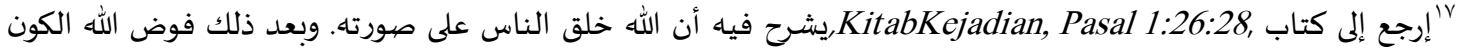

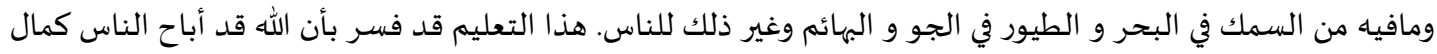
الإباحة لإستغلال ولإستثمار العالم لحوائجهم.
} 
Ri'āyah al-Bī'ah...

لاحظآرني نايس-بناءا على أكبر اهتمامه للناس-أن هذا المذهب من الأخلاقيات البيئية الضخلة, يعني عكس أخلاق البيئية العميق.`و وإذا قورن بالمذهبين الآتيين يكون هذا المذهب في أرذل المذاهب, ويعتبر نايس ناشط البيئة من الأسباب الرئيسية للأزمة البيئية اليوم. لما كان تركيز اهتمام هذا المذهب يقع في الناس وحوائجاء, واجهت هذه النظرة كثيرا من الانتقادات الجارحة. منها رسالة

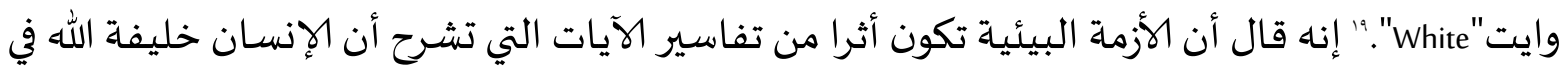
الأرض. هذا وفقا لما شرعتاه الأديان السماوياة, أن للإنسان مقامات عظيمة.أما قدس بعد أن لاحظ تاريخ نشأة "المركزية البشرية Anthropocentrism", يرى أن هذه النظرة تكون نتيجة من سوء الفهم للدين.

\section{التصوف و الأخلاق البيئية}

إذا سئل سائل فقال: لم نسمع بذكر التصوف في أصحاب الرسول ولا فيمن بعدهم, ولا نسمع

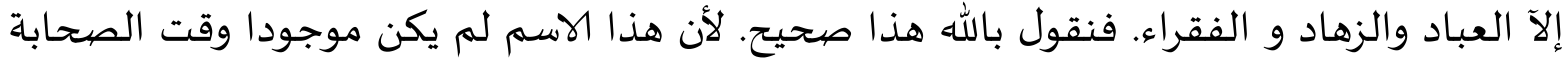

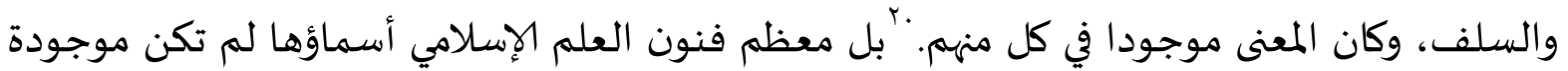

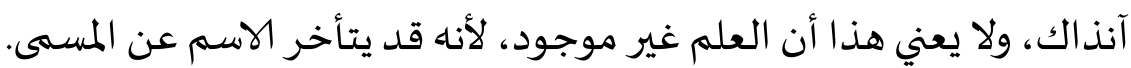
ويبدو أن من أسباب ظهور طبقة العباد والزهاد في القرن الثاني الهجري هو إقبال الناس على

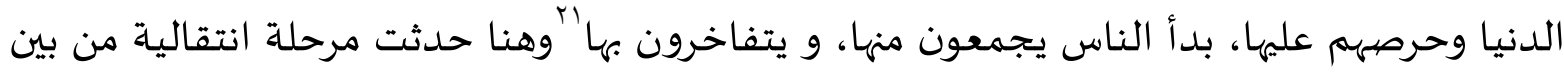
هؤلاء العباد، والزهاد، والفقراء، حيث تطور معنى العبادة والزهد والفقر إلى تسمية جديدة هي اسم

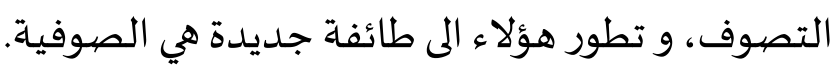

ثم انتشرت حركة التصوف-بشكل أوسع- في العالم الإسلامي في القرن الثالث الهجري كنزعات فردية تدعو إلى الزهد وشـدة العبادة. بَّل لحظ "Sell" أن ظهور التصوف فيكون نقدا عن السلوك و أنماط

"Arne Naess 'N هو أول من عرف إصطلاح "الأخلاق البيئة العميقة" (Deep Ecologi) أنه قادم من"Norwegia".وبعد ذلك عرف

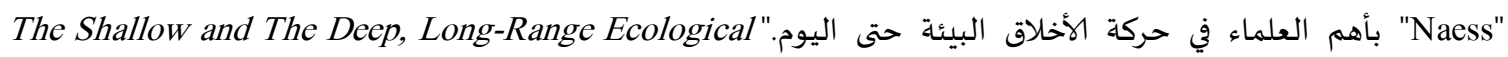

"Movement: A Summary.

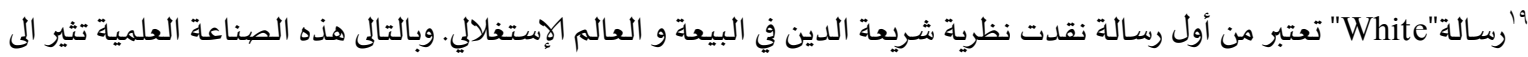

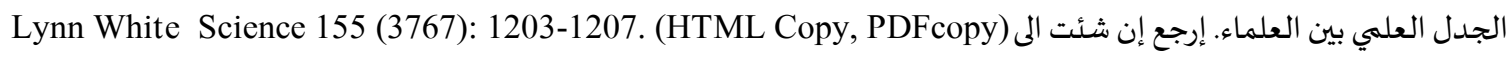

,The Historical Roots of Our Ecological Crisis,"

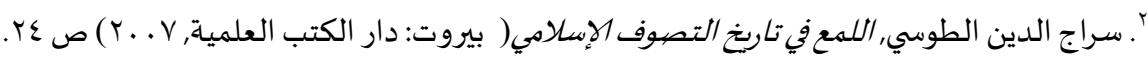

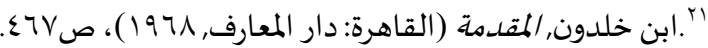

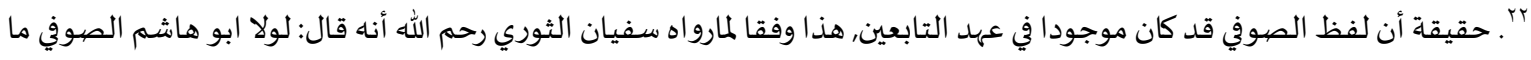

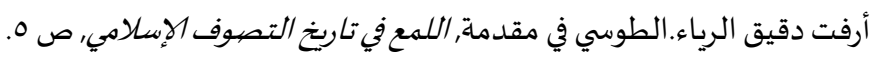

Teosofia: Indonesian Journal of Islamic Mysticism, Volume 5, Number 2, 2016 
العيس التى لم تكن موجودة فى عهد الصحابة ومن سار على نهجهم من التابعين. بَّرى في هذا القرن أنماطا من الحياة لم تكن مؤلوفة من قبل, من التفنن في الطعام و المآدب و حفلآت الزوج التى تنفق فيها

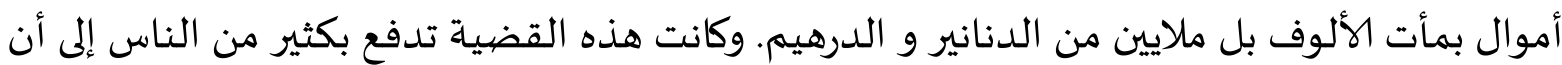

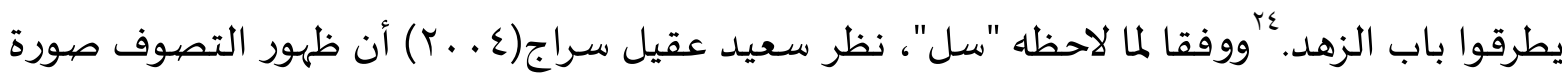
النقد الفعلي"Silent kritik" من المتصـوفين. وهكذا كان الزهد رد فعل مضياد للإنحراف عن الحيات الصيدر

هذا، ثم من ناخياة إجتماعية يمكن أن نقول أن التصيوف على ثلاثة معان, التصوف كأخلاق و

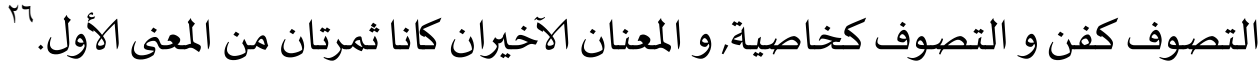

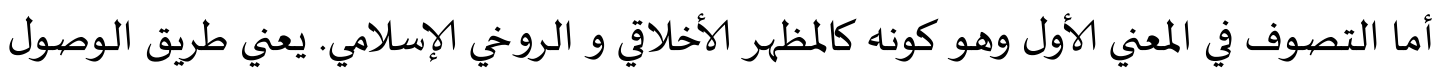
الى التقوى وتزكية النفس السمو الأخلاقى والتحلى بالفضائل الروحية والأخلاقية. وهذا التعريف للتصوف أيده الجريري حيث قال: التصوف هو الدخول في كل خلق سني و الخروج من كل جلق دني. وأيده كذلك الجنيد البغدادي فقال: التصوف خلق, من زاد عليك بالخلق فقد زاد عليك بالتصوف.

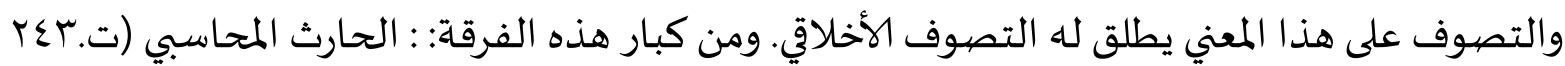

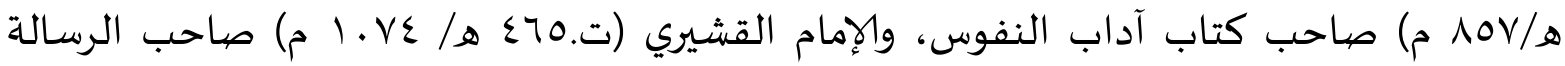
المشهورة، وحجة الإسلام الإمام الغزالي (ت.0 0 هـ/111 م) م) صاحب إحياء علوم الدين، و شيخ الإسلام

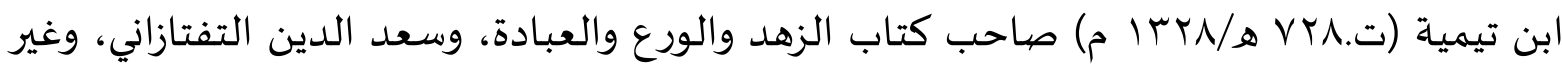

هناك تعريفات كثيرة لأخلاق, ولكنها تعريفات متقاربة. قدم الغزالي تعريف العام, هو عبارة عن هيئة في النفس راسخاة, عنها تصدر الأفعال بسهولة ويسر من غير حاجة إلى فكر ورؤياة، فإن كانت الهيئة

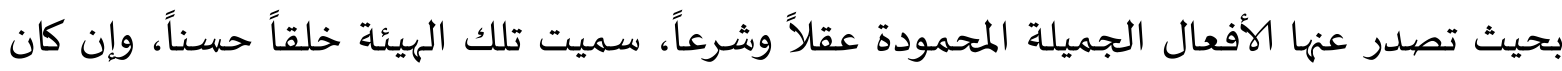

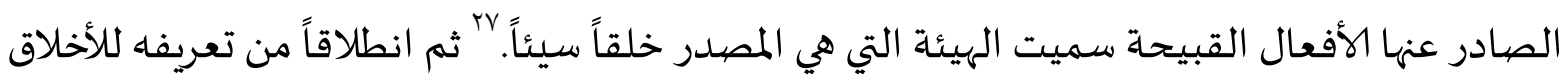

${ }^{23}$.Michael A. Sell, Terbakar Cinta Tuhan (Bandung: Mizan, 2004) 42

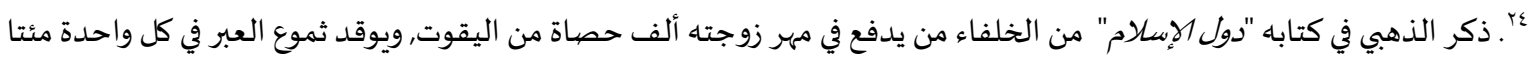

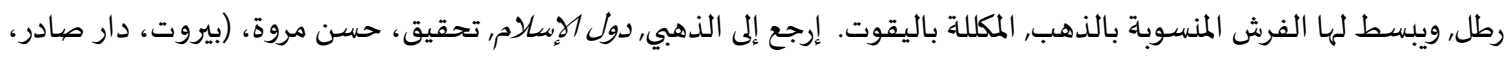

${ }^{25}$ Said AqilSiraj, Tasawuf Sebagai Kritik Sosial (Bandung: Mizan, 2006), 34.

${ }^{26}$ NS, Swito, Eko-Sufisme: Konsep, Strategi dan Dampak (Yogyakarta: ST AIN Press), 37. I' أبو حامد الغزالي، إحياء علوم الدين (بيروت: دار المعرفة للطباعة والنشر)، صr 
يبين لنا الإمام الغزالي شروط الفعل الأخلاقي فيرى أهها أربعة:أحدها: فعل الجميل والقبيح, والثاني: القدرة عليهما, والثالث: المعرفة بهما, والرابع: هيئة للنفس بها تميل إلى أحد الجانبين ويتيسر عليها أحد الأمرين. وعرفه ابن مسكويه بقولهالخلق: حال للنفس، داعية لها إلى أفعالها من غير فكر ولا رويَّة،وهذه الحهال احسيال

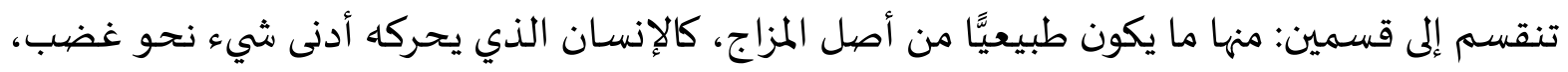
ويهيج من أقل سبب، وكالإنسان الذي يجبن من أيسر شيء، أو كالذي يفزع من أدنى صوت يطوت يطرق سمعاه،

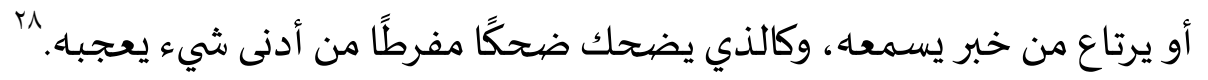
تعتبر القاعدة الأخلاقية من أهم المبادئ التي جاءت بها التصيوف الإسلامي، فالأخلاق تشكل جزءاء مهما من الإسلآم الذي ينبغي أن يلتزم باه المسلم. بل الأخلاق هي الهدف الأسـاسي في بعثة الأنبياء والرسل،

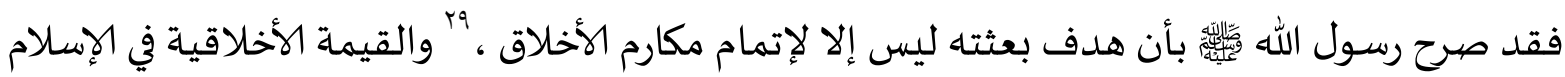
لا تنحصر في أبعادها الإنسانية فحسب، بل تتجاوز ذلك لتنظم علاقة الإنسان بجميع أهل الأرض بما

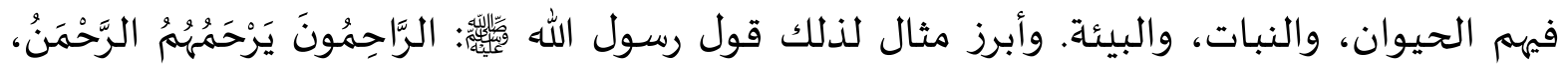

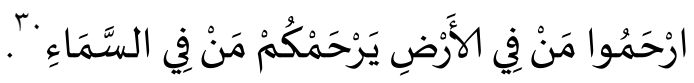

فالأخلاق في الإسلام تمتد لتشمل جميع جوانب النشاط الإنساني وقد أرسى الإسلام دعائم

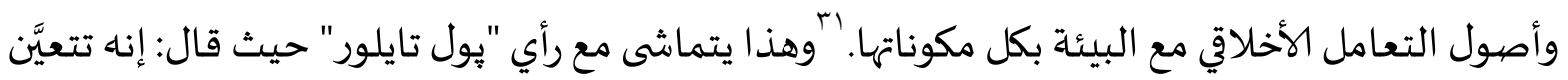

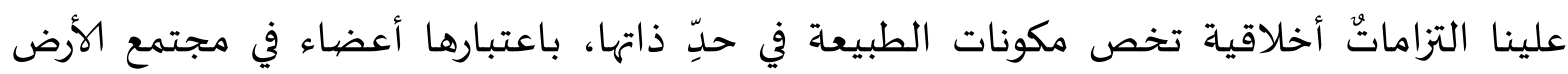
الحيوي. بَ فمفهوم التسخير الذي جاءت باه الشريعة الإسلامية لا يعني الإحساس بالاستعلاء والتدمير. كما كتبه " وايت White" في رسالته نقدا عن شريعة النصرني, بل هو مفهوم مؤطر في إطار الضيوابط الإحسيك

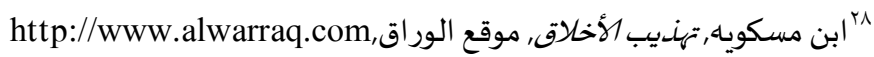

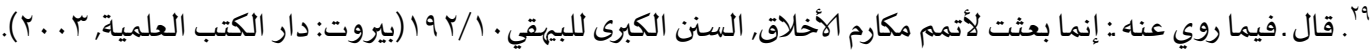

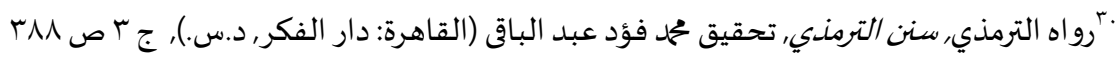

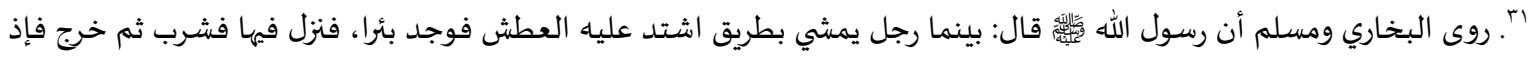

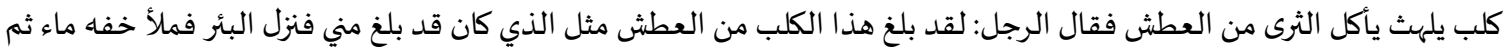

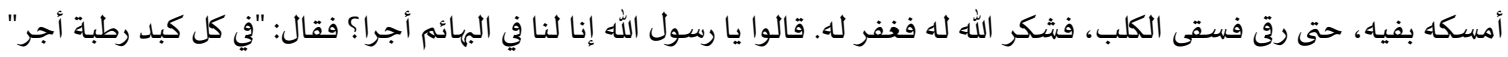

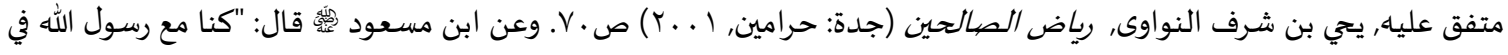

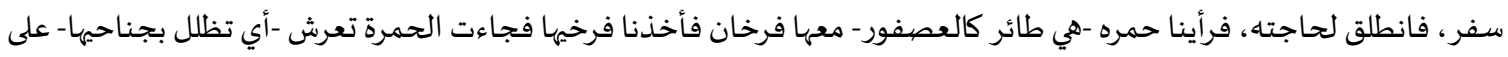

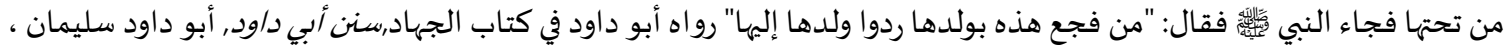

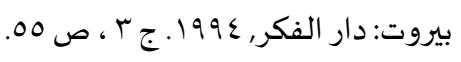

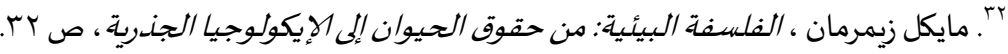

Teosofia: Indonesian Journal of Islamic Mysticism, Volume 5, Number 2, 2016 
الشرعية ومقاصيد الشريعة التي تجعل الإنسان ينتفع ببيئته دون تدمير أو هلاك للحرث والنسل أو العبث بالكائنات.

و وجود الاعتدال في الانتفاع, يكون خصصية من خصائص السلوك الإسلامي ومقصد الإسلام في الحث على هذا الخلق هو حفظ توازن النوع الإنساني والبيئي، فلا ينتفع الإنسان بالبيئة إلا بالقدر الذي يحفظ استمرار النوع، وإعمارة الكون، ولا يتسبب في تدمير البيئة والإخلال، بالتوازن البيئي مما

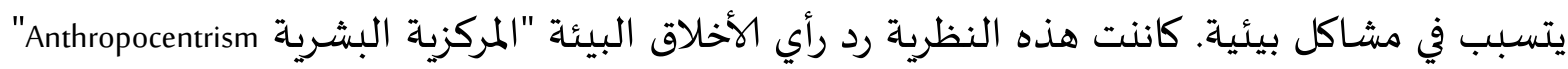
التى تراى أن أفعال البشر تجاه الطبيعة تكون صحيحة أو خاطئة وفقًا لمدى تناسُبها مع "خير" الإنسان.

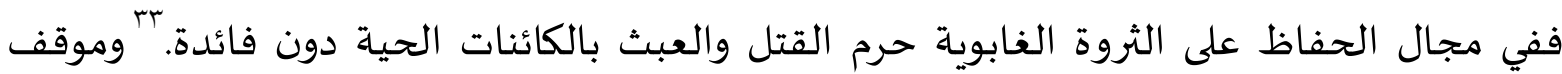

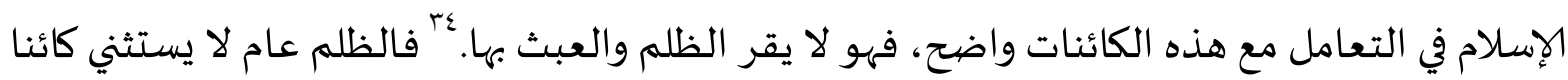
دون آخر ، بل لكل كائن حقوق معينة رسمتها الشريعة، ووضعت أصهول وقواعد التعامل معها. و و مشروعية الرحمة في التعامل مع هذه الكائنات تستهدف تربية المسلم وتعويده على الشعور بأمانة الاستخلاف على هذه الكائنات، فلا يأخذ الموارد في ما لا منفعة فيه ولا يطغى ويتجبر على هذه الكائنات وكأها لا تحس ولا تشعر بظلم الإنسان إنها كائنات تحس وتشعر ولكننا نحن الذين لا نفقـه إحساسها. روى وكيع عن أبي بكر الهذلي، عن أبي قلابة قال: من ذبح عصفورا عبثا، جاء يوم القيامة يعج، قال، لم يذبحني فيأكلني، ولم يدعني أعيش في حشراتها. وفيما يتصل بموضوعنا فإن الإرشادات الإسلامية التي تساهم في حماية البيئة وفيرة ومتنوعاة، وبعضها يعتبر إرشادات عامة تصلح للتوجياه في حماية البيئة بكافة عناصرها، وبعضها تمثل إرشادات خاصحة تنفع للتوجياء في مجالات محددة، و التصوف يلعب دورا كبيرا في هذا الموضع.

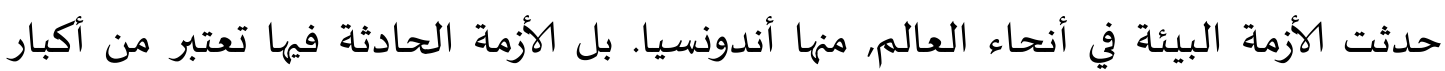

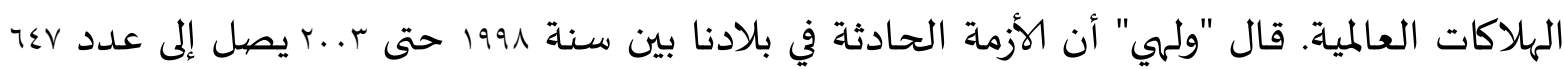

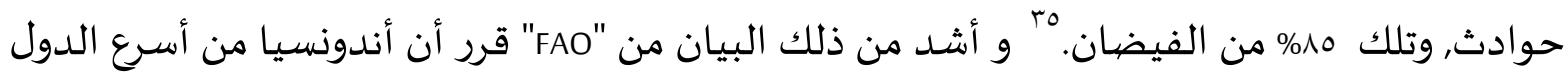
Komprehensif (Jakarta: Pskasarjana UIN Jakarta 2007), 45. 
Ri'āyah al-Bỉ'ah...

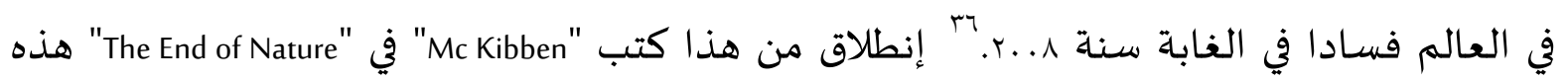
الكتابة تكون صورة الإهتمام لأزمة البيئة العالمية.

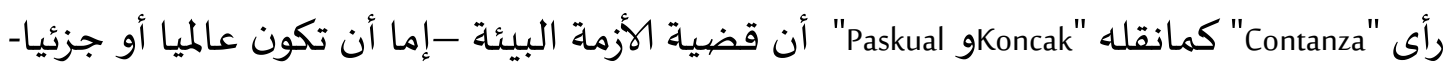
أثر من جسع الإنسـان وطمعه. "َّ و أيد هذا الرأي "Enoch" أن عمل الإنسان الصناعي لا يهتم بالأمور

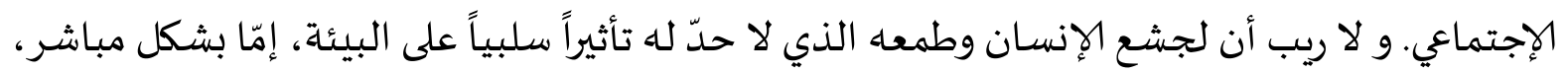
لأن زيادة استهالك الإنسان للمنتجات على اختلاف أنواعها الغذائية أو الصناعية أو غيرها تتبع زيادة

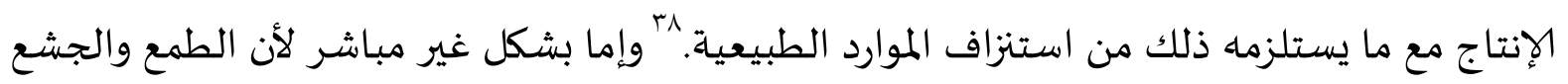
يقود الإنسان في كثير من الحالات إلى التقاتل و الحروب والصراعات وهي بطبيعة الحال تدمر الكثير من مظاهر البيئة وعناصرها.

ومن هنا فإنّ مفهوم الزهد الذي قدمه التصوف يمكنها أن يلعب دوراً كبيراً في هذه القضية، لإناه يروّض الإنسان على القناعـا، ويحدّ من نزعاة الجشع والطمع لدياء. وإن بعض مظاهر الطمع يمكن

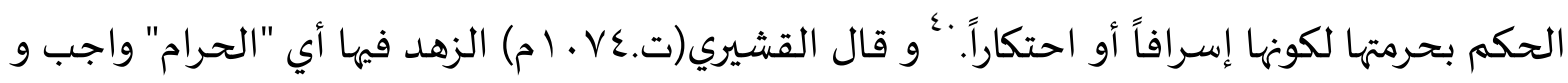

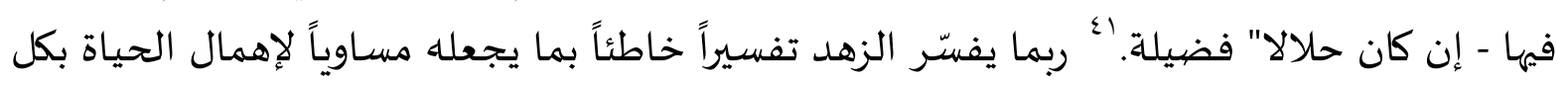

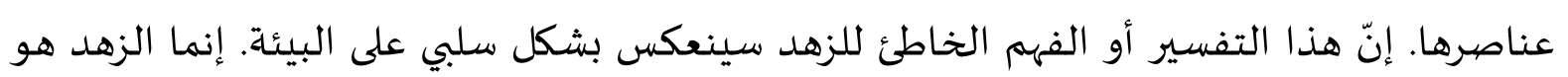

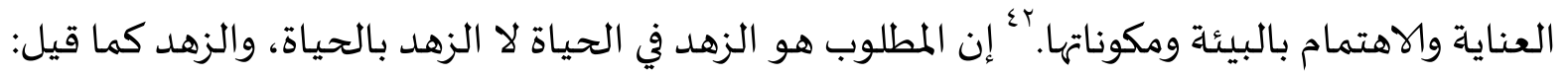

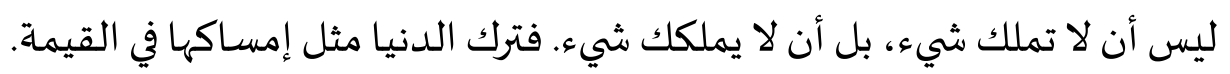
من خلال ما تقدم لم يبق شك في أن الإهتمام التصيوفي التي جاءت بها الشريعة الإسلامية بموضوع النظام الأخلاقي "شامل فياه أخلاق البيئة" واضح جدا. و التصوف كمظهر من مظاهر الإسلام يتركز في العلاقة بين الإنسان والخالق الأخلاقياة, و التعامل الأخلاقي مع هذه الكائنات. وفي هذا الموضوع

${ }^{36}$ Sudarsono, Menuju Kemapanan Lingkungn Hidup Jawa (Jogjakarta: PPLHRJ, 2007), 129.

${ }^{37}$ Wiliam Konchak and Unai Paskual,Covergin Paradigm for Co-Evalutionary Enveronmental Limit Diascorese, Environmental Economy and Policy Research, 14, 2005: 3

أن فساد الرٔرض يكون أثرا من استنزاف الموارد الطبيعية, و تلوث الأرض, و الماء و الجوي. Human Radically altered the Nature of The Planet- Waring its Climate, Depletingits Resaourses, Poluting its oil, water and

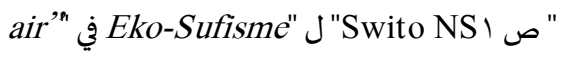

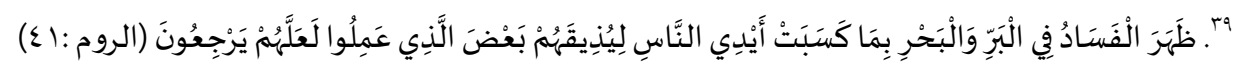

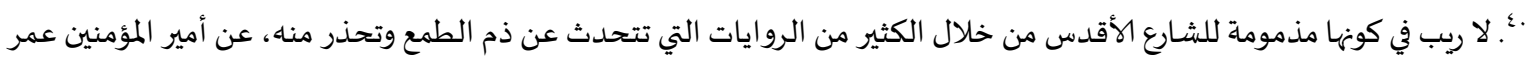

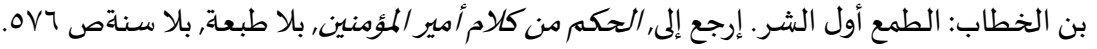

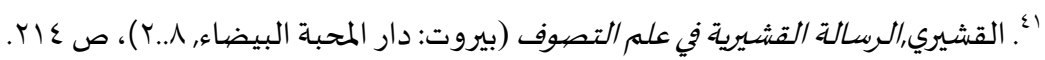

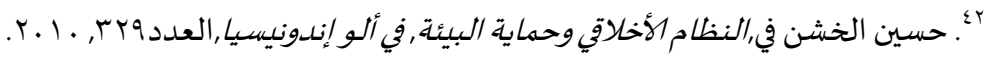

Teosofia: Indonesian Journal of Islamic Mysticism, Volume 5, Number 2, 2016 
نظر الإسلام -كمصدر التصوف- أن لجميع المكونات قيم ومنافع, و كل يسبح الله. بّع من مفاهيم وتعاليم التصوف الإسلامي أن العلاقة الإكولوجية لاتنحسر على العلاقة الإنتفاع والإستفادة وحسب. بل أن للتصوف مفاهم أفضل من ذلك. لم ينظر التصيوف إلى المكونات كمتعة مجردة، ولكنها ينظر إليها كآيات

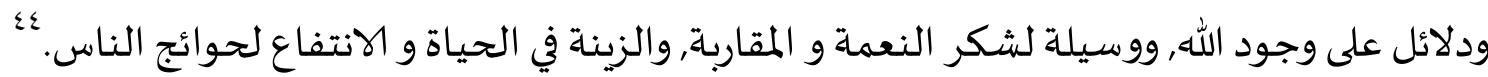

\section{العلاقة بين الله و العالم}

كان الكلام حول هذا الموضع مهما في هذا الباب, لأن معرفة هذه العلاقة سوف يساعدنا في فهم

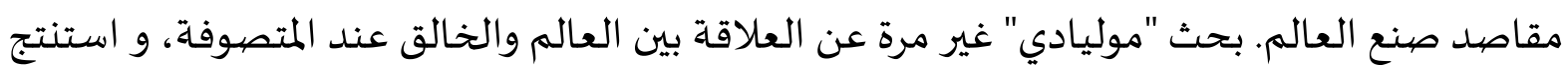

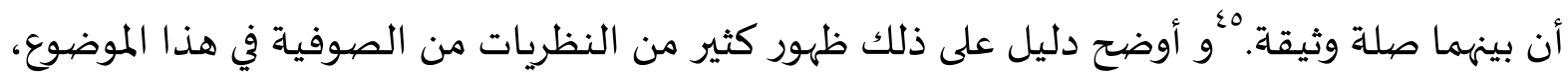
على الأقل فياء ثلاثة أقوال: منها النظرية الإشراقية التي قدمها السّهرورديّي(ت بrآ), تعتبر هذه النظرية من الصوفية لأن طريقة الإستنباط المعرفة تتمّ عن طريق ظهور الأنوار العقليّة و الإكتشاف.

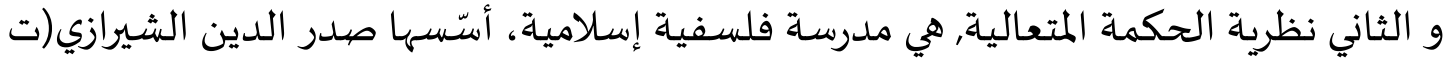

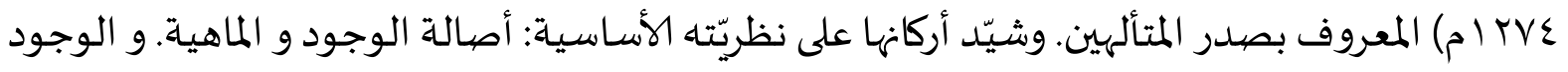
عنده ليس بالماهية. وتتميز هذه المدرسة باستقائها من مصادر الدين الإسلامي الأساسية كالقرآن والروايات المعتبرة من الأحاديث, ومن الوجدان والشهود فضلاً عن اعتمادها على المنهج العقلي البرهاني.

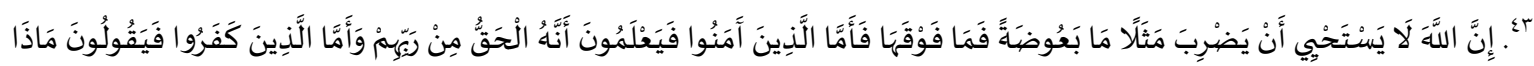

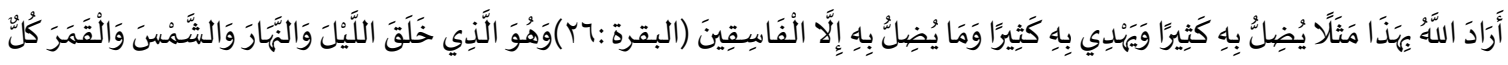

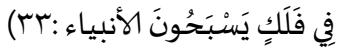

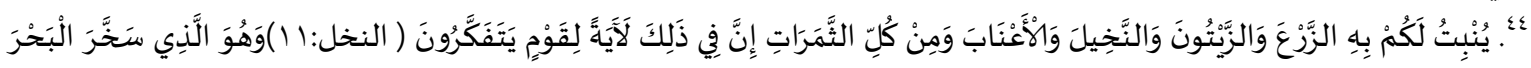

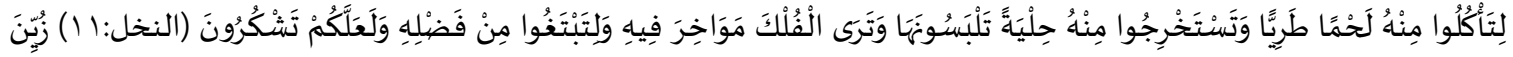

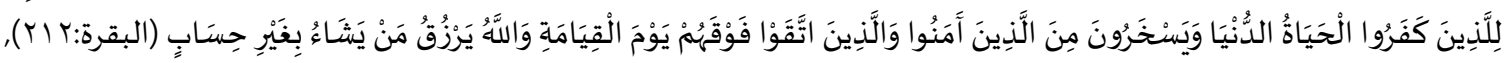

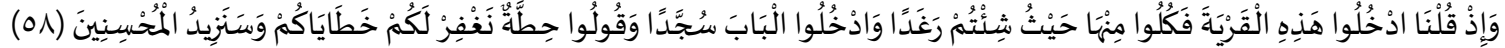

${ }^{45}$ Mulyadi Kartanegara, Menyelami Hakikat Tuhan, Manusia dan Alam (Jakarta: Erlangga 2007), 18-30

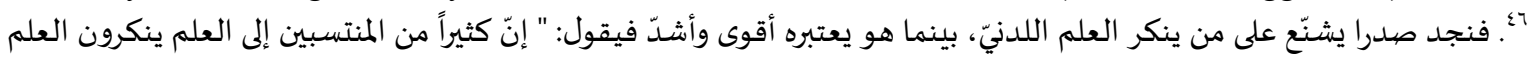

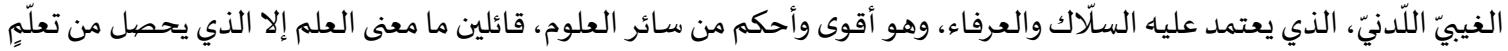

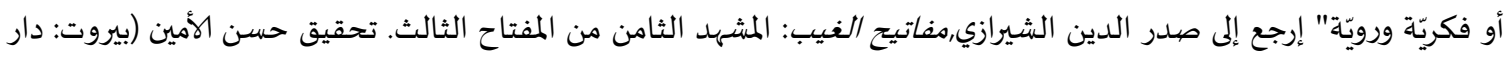

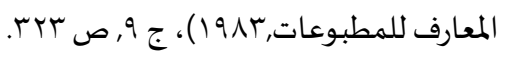


والثالث نظرية الغزالي(ت / 11 ( 1 م), و هو يرى أن ما سوى الله محدث و مخلوق و منتج إلهي، و في

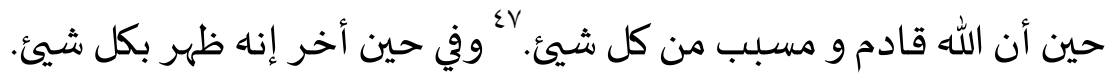

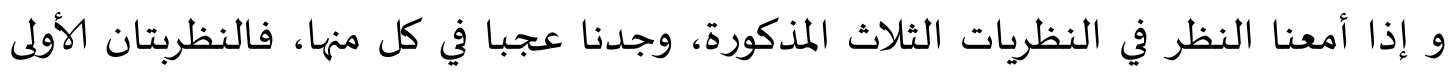

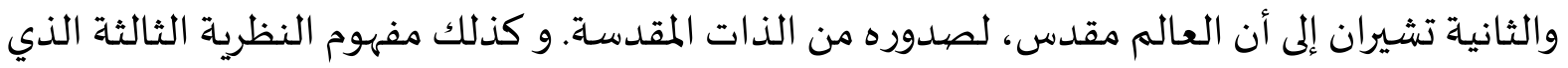

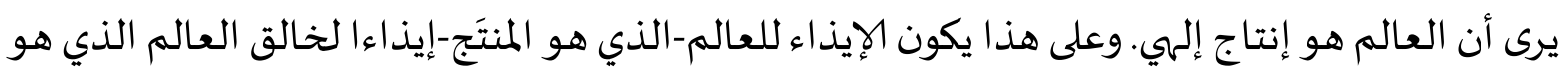

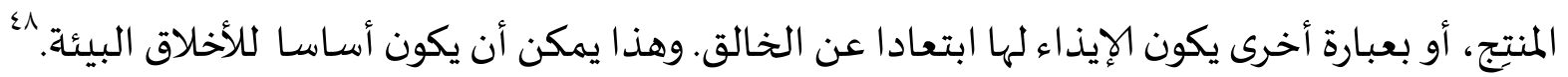

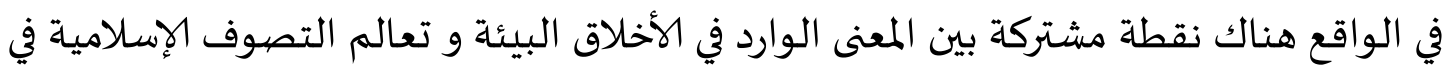

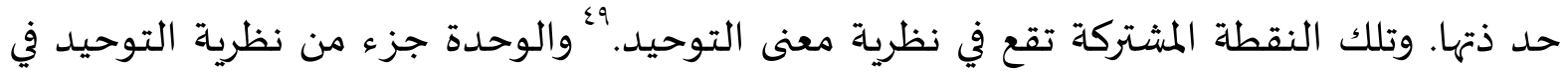
الإسلام. وفقا من هذ المفهوم أن الحياة تصدر من الوجود الحقيقة, و في جوهرها أن الحياة مجلى نالى

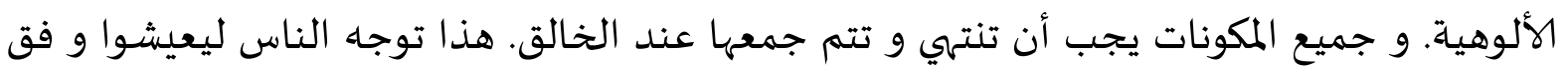
المبادى العادلة و المساومة و التسامح لجميع المكونات في أجل النيل على رضى الخالق.

ج. نتيجة البحث أن الإهتمام التصوفي التي جاءت بها الشريعة الإسلامية بموضوع النظام الأخلاقي "شامل فيه

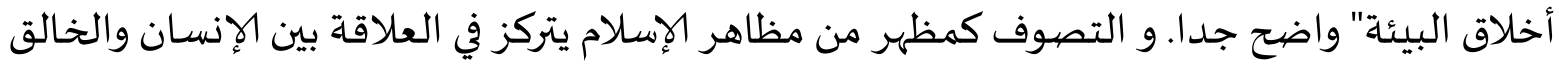

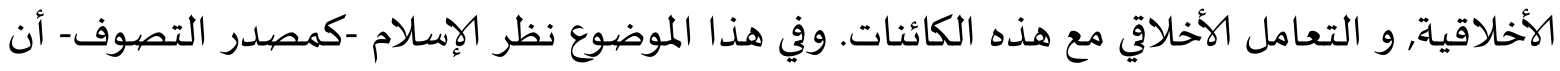
لجميع المكونات قيما ومنافع، و كل يسبح الله. أن المككنات مظاهر من مظاهر الخالق. وكل خاضع لقانون واحد وسنّاتة واحدة تتحكم في

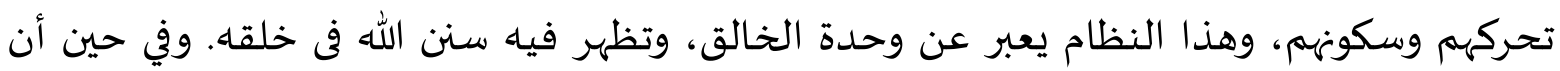

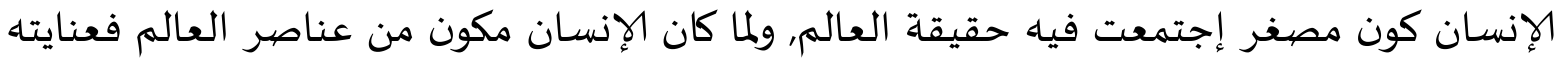

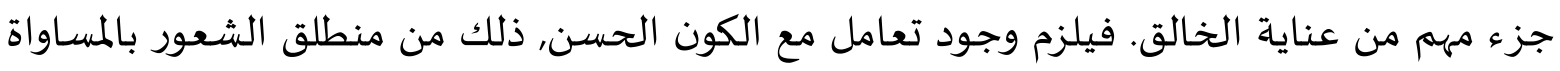
معها والمشاركة في العبودية لإله واحد، وترتبط علاقاته بغيره بمدى تعلقهاه والتفاته إلى ربها.

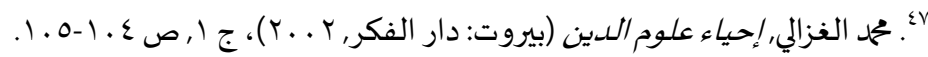

$$
\begin{aligned}
& \text { 0. صSwito NS. ¿^ }
\end{aligned}
$$

${ }^{49}$ Hossein Nasr, Science and Civilization in Islam, dalam http//www.fordham/halsall/med/nasr.html. diakses pada 25 Januari 2013.

Teosofia: Indonesian Journal of Islamic Mysticism, Volume 5, Number 2, 2016 


\section{Bibliography}

Nasr, Sayyed Hossein, “Islam dan Krisis Lingkungan”dalam "Islamika”, Jakarta: Mizan dan Missi, No 3, Januari-Maret, 1994.

Noer, Kautsar Ashari, Ibn Arabi: Wahdatul Wujud dan Perdebatan. Jakarta: Paramadina, 1995.

Murata, Sachico, The Toa of Islam. Terj, RahamaniAstutidan MS. Nasrullah. Bandung: Mizan, 1996.

Ali, Yunasril, Manusia Citra Ilahi, Jakarta: Paramadina, 1997.

Eafifi, A., Filsafat Mistis Ibn 'Arabi, trans. Sjahrir Mawi dan Handi Rahman, Jakarta: Gaya Media, 1989.

Keraf, Sony, EtikaLingkungan. Jakarta: Kompas, 2006.

Cang, William, Moral Lingkungan Hidup, Jogjakarta: Kaniius, 2000.

Swito. NS., Eko-Sufisme: Konsep, Strategi dan Dampak. Yogyakarta: STAIN Press, 2011.

Sell, Michael A.Terbakar Cinta Tuhan. Terjemah Al-Fatri . Bandung: Mizan, 2004.

Siraj, Said Aqil, Tasawuf Sebagai Kritik Sosial . Bandung: Mizan, 2006.

Hadi, S. Ali Kodra, Kapasitas Pengelolaan SDA dan Lingkungan Hidup, Diktat Seminar Kajian Islam Komprehensif, Jakarta: Paskasarjana UIN Jakarta, 2007.

Sudarsono, Menuju Kemapanan Lingkungn Hidup Jawa. Jogjakarta: PPLHRJ, 2007.

Konchak, Wiliam and Paskual, Unai, Covergin Paradigm for Co-Evalutionary Enveronmental Limit Diascorese, Environmental Economy and Policy Research, 2005.

Negara, Mulyadi Karta, Menyelami Hakikat Tuhan, Manusia dan Alam. Jakarta: Erlangga, 2007.

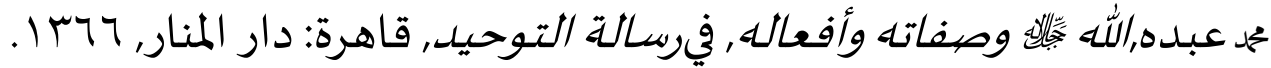

$$
\begin{aligned}
& \text { ابن عطاء الله السكندري, الحكمى, جدة: حرامين, د.س.. } \\
& \text { ابن عربي, الفتوحات المكية ,قاهرة: دار الكتب العلمية, بيروت, } 7 \text {. . r. } \\
& \text { ابن تيمياة, مجموع الفتوى, بيروت: دار العربية, روسا . } \\
& \text { سراج الدين الطوسي, اللمع في تاريخ التصيوف للسبامي, بيروت: دار الكتب العلمية, V . . r. } \\
& \text { ابن خلدون, المقلدمة, القاهرة: دار المعارف, } 1971 . \\
& \text { أبو حامد الغزالي إحياء علوم الدين، بيروت: دار المعرفة للطباعة والنشـر،د.س. جمَ. } \\
& \text { سنن أبي داود, أبو داود سليمان ، بيروت: دار الفكر, ع99 } 199
\end{aligned}
$$




$$
\text { أبن رشدل، بديمرمان ، الفلسفة البيئية: من حقوق الحيوان إلى الإيكولوجيا الجندرية. }
$$

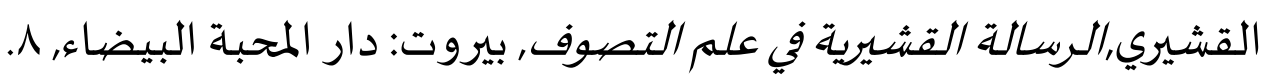

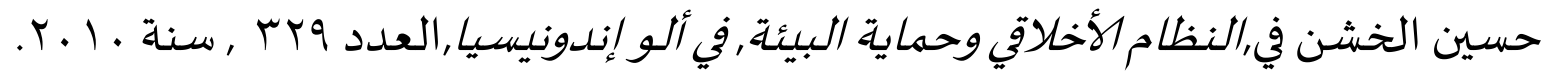

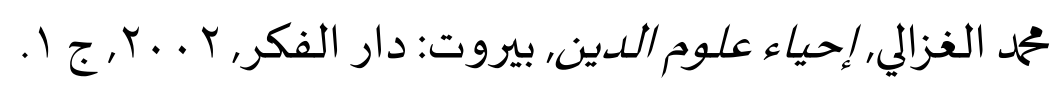

